Filozofski fakultet

Univerzitet u Novom Sadu

\title{
PRIGODNI RAZGOVOR SA RANKOM BUGARSKIM O SADAŠNJOSTI, PROŠLOSTI I BUDUĆNOSTI LINGVISTIKE
}

Ime i delo profesora Ranka Bugarskog dobro je poznato generacijama studenata jezikâ i lingvistike na svim univerzitetima u Srbiji i bivšoj Jugoslaviji. Iz njegovih brojnih knjiga i bezbrojnih članaka učili su, uče i učiće kako mnogobrojni studenti jezikâ i lingvistike, tako i oni koji su im predavali, predaju ili će tek predavati jezike i lingvistiku. Bugarski se oprobao, dokazao i afirmisao u oblastima anglistike, opšte lingvistike, sociolingvistike, primenjene lingvistike, kontrastivne lingvistike, kontaktne lingvistike i srbistike, ostavljajući originalne i neizbrisive tragove u nebrojenim domaćim i inostranim publikacijama. ${ }^{1}$

Pored svoje zavidne naučnoistraživačke produkcije, koja traje bezmalo šest decenija $i$, na sreću, ne pokazuje znake posustajanja ili zamora (najnovija njegova knjiga jeste Govorite li zajednički?, Biblioteka XX vek, Beograd, 2018), Bugarski je jedinstvena pojava u domaćoj, i ne samo domaćoj, akademskoj zajednici i po najmanje sledećim činjenicama: biran je dva puta za redovnog profesora - prvo Engleskog jezika, a zatim Opšte lingvistike, na Filološkom fakultetu u Beogradu; član je Evropske akademije nauka i umetnosti (Academia Scientiarum et Artium Europaea), sa sedištem u Salcburgu; bio je mentor 46 predbolonjskih magistarskih radova i 12 doktorskih disertacija; i, ne na poslednjem mestu, posvećena su mu četiri festšrifta, odn. prigodna zbornika, s radovima njegovih kolega i prijatelja, delom njegovih bivših studenata, što je pažnje vredan presedan, nepoznat čak i u svetskim razmerama - najnoviji takav zbornik jeste specijalno izdanje časopisa Belgrade English Language and Literature Studies (Belgrade BELLS), Special Issue in Honour of Ranko Bugarski on the Occasion of His 85th Birthday, broj 10/2018, koji su na Filološkom fakultetu u Beogradu uredile Katarina Rasulić i Ivana Trbojević Milošević. ${ }^{2}$

\footnotetext{
*tvrtko.prcic@gmail.com

${ }^{1}$ Celovit popis radova R. Bugarskog, do 2018. godine, pruža Bibliografija uz Sabrana dela, 9., dopunjeno izdanje, Čigoja štampa, XX vek, Beograd, 2018.

${ }^{2}$ Elektronsko izdanje ovog broja časopisa besplatno je dostupno na adresi: http://www.belgrade.bells.fil.bg.ac.rs/Bells\%2010.pdf.
} 
Ovaj prigodni zbornik, u celosti na engleskom jeziku, sadrži četrnaest značajnih studija, većinom iz primenjene $i$ kontrastivne lingvistike i sociolingvistike, kojima autorke i autori izražavaju svoje poštovanje i zahvalnost dedikatu, povodom njegovog 85. rođendana. Pečat ovom specijalnom broju Belgrade BELLS-a nesumnjivo daje uvodni intervju s Rankom Bugarskim, inače stalna i u našoj sredini dosad retko viđana, ali hrabra i inovativna rubrika ovog časopisa. Iscrpan, sadržajan, poučan i zabavan razgovor, kojem su podjednako doprineli, s jedne strane, odgovori intervjuisanog - kratki, sažeti, jasni, dosetljivi, ponekad duhoviti ili ironični, ali uvek kompetentni i autoritativni, i, s druge strane, pitanja intervjuerke Katarine Rasulić, koja je, i ovog puta uspešno, primenila svoje dugogodišnje novinarsko znanje i iskustvo, sticano, uz ostalo, i u efektnom informativno-zabavnom mini tok-šouu Dvougao, čiji je koautor i narator. Pomenuti intervju deluje kao svojevrsni scenario za dokumentarni film koji prati sve bitne aspekte profesionalnog života i rada Ranka Bugarskog, polazeći od njegovih početaka, 1961. godine, kada je izabran za asistenta na Filološkom fakultetu u Beogradu, preko njegovog školovanja i usavršavanja u zemlji i inostranstvu, te njegovih glavnih lingvističkih stavova iznesenih u knjigama i člancima, pa zaključno $\mathrm{s}$ današnjim danima i njegovim mudrim savetima budućim lingvistima. $\mathrm{Na}$ kraju ovog izuzetno vođenog intervjua, informativnog $\mathrm{i}$ inspirativnog $\mathrm{u}$ isto vreme, zainteresovani čitaoci shvataju da su saznali, na lep i slikovit način, sve ono što su 'oduvek' želeli da znaju ili saznaju o Ranku Bugarskom, a nisu imali gde. S malo vizuelne mašte, pred njihovim očima prikazan je biografski film o životu i radu dedikata, film, i intervju, pod naslovom „Lingvistika kao nauka o čoveku”, tj. Linguistics as a science of man, kojem možda nedostaje upotpunjujući podnaslov „viđena očima jednog velikog čoveka”.

$\mathrm{Na}$ promociji održanoj dana 10. maja 2018. godine, na Filozofskom fakultetu u Novom Sadu, predstavljeni su knjiga Govorite li zajednički? i ovaj prigodni zbornik. Kourednica Katarina Rasulić pomenula je prethodna tri zbornika, opisala nastajanje ovoga, od ideje do realizacije, i ukratko prikazala sadržaj svih 14 priloga, dok je dedikat biranim rečima govorio o značaju zbornika, te o urednicama, autorkama i autorima prilogâ. Predstavljanje prigodnog zbornika sastojalo se i od posebnog razgovora, ili možda intervjua, s Rankom Bugarskim, ali malo drukčijim od onog štampanog. Naime, združeno podstaknut sadržajem intervjua Katarine Rasulić i formatom izvedbe Dvougla, u kojem se ista pitanja postavljaju dvema osobama, sličnih, ili, znatno češće, suprotstavljenih, mišljenja, preznatiželjni intervjuer Tvrtko Prćić teleportovao je svojim pitanjima intervjuisanog Ranka Bugarskog u različite vremenske dimenzije, koje obuhvataju raspon od oko jednog 
veka - između 50-ak godina u prošlost i 50 -ak godina u budućnost, s povremenim zadržavanjima u sadašnjosti. Pored ovoga, pitanja su iziskivala veće ili manje angažovanje kritičke i/ili samokritičke introspekcije. Putujući s nama u ovom svojevrsnom akademskom lingvoplovu, zainteresovani čitaoci uvideće, kad se udube $\mathrm{u}$ ponuđene odgovore, jezgrovite $\mathrm{i}$ nabijene značenjima, sasvim $\mathrm{u}$ dedikatovom prepoznatljivom wit-and-pith, tj. dosetljivost-i-jezgrovitost, stilu, da su iz njih saznali sve ono što 'oduvek' ni sanjali nisu da će saznati o Ranku Bugarskom, jer niko nije sakupio hrabrosti da ga to upita - snovi su se, eto, raspršili.

Sledi pisana verzija pet lingvoplovnih pitanja i odgovora, odgovora opet informativnih i inspirativnih, koje je intervjuisani lično napisao i time postao (nepotpisani) koautor ovog priloga.

Od svojih akademskih početaka, 1961. godine, do danas, bili ste svedok, pa i protagonista, nastajanja novih lingvističkih disciplina ili teorijsko-metodoloških orijentacija postojećih disciplina. Koje od njih smatrate naučnoistraživački najvrednijima i najkorisnijima?

Sticajem okolnosti, moj razvojni put u lingvistici prošao je kroz nekoliko etapa. Prvu je obeležio strukturalizam, koji je ostavio trajan trag u mom razmišljanju o jeziku. Za njim je došla transformaciono-generativna gramatika, koju sam doživeo kao izdanak strukturalne lingvistike pre nego kao zamenu za nju, i koja je moju pažnju držala srazmerno kratko jer nisam bio sklon njenom strogom formalizmu. U velikoj meri samouk, nisam se trajno vezivao ni za koju užu teorijsku ili metodološku paradigmu. U svojim prvim ozbiljnijim istraživanjima, uključujući naročito doktorsku disertaciju o podsistemu engleskih predloga za vertikalnu orijentaciju u prostoru, izgradio sam sopstveni višedimenzionalni analitički sistem koji je, po oceni kompetentnih komentatora, predstavljao svojevrsnu najavu kognitivne lingvistike. Pretpostavljam da ste najpre na to ciljali nazivajući me protagonistom nekih novih orijentacija. Ubrzo potom moja interesovanja za društvene aspekte jezika odvela su me ka sociolingvistici. Teško mi je da kažem šta od pomenutog u nekom apsolutnom smislu smatram najvrednijim i najkorisnijim, jer sve to vidim kao kamenčiće $u$ jednom šarenom i bogatom mozaiku, ali ako bih bio primoran da se izjasnim sada bih izvesnu prednost ipak dao kognitivnoj lingvistici, za koju mislim da najviše obećava. 
U narednih 50 godina sigurno će se pojaviti novije lingvističke discipline ili teorijsko-metodološke orijentacije. Koje bi od njih Vas lično najviše obradovale?

Kad me već projektujete pola veka u budućnost, u svom odgovoru počeću od istog vremenskog odsečka u prošlosti, kad je počelo ono što je neposredno relevantno za Vaše pitanje. Konkretno, u mislima se vraćam u 1972. godinu, jednu od najvažnijih u mojoj akademskoj karijeri, kada su objavljeni moja knjiga Jezik $i$ lingvistika (koja će dobiti uglednu Nolitovu nagradu) i moj izbor radova Čomskog pod naslovom Gramatika i um. Ali za trenutnu temu važnije od toga je predavanje koje sam iste godine održao na Filozofskom fakultetu u Sarajevu, naslovljeno „Lingvistika kao nauka o čoveku”, koje će naredne godine biti štampano u časopisu Izraz a potom uneto, kao prvo poglavlje, u knjigu Lingvistika o čoveku u ediciji XX vek Ivana Čolovića, 1975. godine. Ovi karakteristični naslovi, kao i naslov intervjua koji je Katarina Rasulić vodila sa mnom za ovde predstavljeni zbornik radova u moju čast, "Linguistics as a science of man", odslikavaju moju tadašnju viziju koja me do danas nije napustila - jedne obuhvatne buduće nauke o jeziku, antropološki zasnovane, koja bi u sebi objedinila strukturalne, funkcionalne, psihološke, sociološke i druge komponente. Tako lingvistika ne bi više bila samo nauka o jeziku nego, po mojoj zamisli, jezički deo jedne šire nauke o čoveku. Takva lingvistika tada nije postojala, niti postoji danas, bezmalo pola veka kasnije, ali bih se najviše obradovao ako bi se u narednih 50 godina na horizontu ukazala makar $\mathrm{u}$ nacrtu.

U odgovoru na Katarinino pitanje koji su lingvisti na Vas najsnažnije uticali, pominjete i Noama Čomskog. Danas ste obojica svetski poznati angažovani intelektualci, nesporni, citirani i pitani autoriteti $u$ svojim oblastima, pri čemu Vas razlikuju dve neizbežne datosti: Čomski je pet godina stariji od Vas (7. decembra ove, 2018, godine puni 90 godina), $i$, iz razumljivih razloga, Čomski ima znatno veću globalnu medijsku dostupnost od Vas. Pored ovih, koje suštinske naučničke razlike i sličnosti uočavate između Vas dvojice?

Hvala na nezasluženom komplimentu, ali ima još jedna neizbežna datost, a to je naprosto nemerljiva razlika u formatu i statusu, koju valjda ne moram objašnjavati. Biće zanimljivije da odmah odgovorim na pitanje iz Vaše poslednje rečenice. Ne vidim neku suštinsku naučničku sličnost, tim pre što nam se polja 
interesovanja drastično razlikuju, ali bih ukazao na jednu bitnu razliku. Kao naučnik, Čomski je čovek jedne misaone paradigme, jednog sklopa ideja i preokupacija, koji sve što je izvan tog vidokruga odbacuje - da se poslužim njegovim omiljenim izrazom, karakterističnim za polemike koje je često vodio sa oponentima - kao neinteresantno ("of no interest"). Prava lingvistika je ono što njega interesuje, a sve ostalo može biti ovo ili ono ali nije lingvistika. Nasmešio sam se tu skoro kad je, upitan na televiziji N1 ima li šta da doda tekstu Deklaracije o zajedničkom jeziku, koju je upravo potpisao, rekao da nema ništa interesantno ("nothing of interest") što bi mogao dodati onome što tamo piše. Nasuprot tome, ja sam po svom naučnom profilu izrazito eklektičan, uzimao sam sa raznih strana i daleko sam od svake autoritarnosti ili isključivosti. Ovaj kontrast je činjenične prirode i ne podrazumeva nikakav vrednosni sud.

Pre 50 godina u Jugoslaviji je u upotrebi bio srpskohrvatski odn. hrvatskosrpski jezik. Danas su na razvalinama Jugoslavije u upotrebi srpski, hrvatski, bosanski / bošnjački i crnogorski jezik. Koji će jezici, ili jezik, a da to ne budu engleski ili anglozajednički, biti u upotrebi na bivšejugoslovenskom prostoru kroz 50 godina?

Najpre jedna terminološka upadica. U nizu jezika koje nabrajate stoji i bosanski / bošnjački, formulacija koja se kod nas često koristi. Ovo je krajnje redak slučaj dvogubog lingvonima, pri kome kosa crta u pisanju ima značenje 'odnosno', što upućuje na nesklonost ka opredeljenju za jedan ili drugi njegov član. Ona proističe iz svesti da izbor jednog od njih može imati određene političke implikacije, kao i želje da se on zbog toga izbegne. Ovo nije mesto za širu raspravu, a u oba slučaja ima argumenata i za i protiv, ali verujem da će našoj publici biti zanimljivo saznanje da je, bez obzira na lične simpatije i odgovarajuću praksu, ozakonjen samo oblik bosanski. To je zvanični naziv jezika u BiH kao matičnoj državi većine Bošnjaka, ujedno i jezika bošnjačke nacionalne manjine u Srbiji, pa je sledstveno tome država Srbija, pristupajući 2006. godine Evropskoj povelji o regionalnim ili manjinskim jezicima, u svom ratifikacionom dokumentu, kao i u pratećem zakonu donetom u tu svrhu, među deset jezika za koje preuzima obaveze zaštite navela bosanski (Bosnian) a ne bošnjački (Bosniak).

A sada na Vaše pitanje. Nezahvalno je prognozirati šta će se $\mathrm{s}$ jezicima dešavati kroz pet decenija, ali pošto to ipak nije dugačak period u životu jezika dozvoliću sebi procenu da će u upotrebi ostati manje-više isti jezici koji su danas na sceni, i pod istim imenima, a uz engleski kao prvi strani jezik. (Usput registrujem duhovitost naziva anglozajednički umesto sadašnjeg anglosrpskog.) Naime, posle 
jezičkih raskola i usitnjavanja kroz koje smo prošli ne vidim neke nove realne kandidate za lingvističko osamostaljenje. Pošto na Balkanu još uvek važi dogma iz XIX veka o navodno prirodnom i poželjnom jedinstvu jezika, nacije i države, a novih nacija niti država na ovom prostoru nema više na horizontu, ne može se očekivati ni neki nov jezik. Teorijski, ako bi se Vojvodina u nekom scenariju otcepila od Srbije mogla bi se pojaviti ideja o vojvođanskom jeziku kao njenom glavnom simbolu, ali mi to ne izgleda nimalo verovatno. Još su manje izgledni jezici subregionalnog, lokalnog nivoa, tipa šumadijskog ili vranjanskog, kakve u svom neznanju kao navodno paralelne povremeno zazivaju protivnici bosanskog ili crnogorskog jezika. S druge strane, ne vidim da nekom od sada priznatih jezika preti nestajanje, tako da ne predviđam značajnije poremećaje aktuelne situacije u dogledno vreme.

Šta biste kao Ranko Bugarski, 85-godišnjak, savetovali Ranku Bugarskom, 28-godišnjaku, na početku akademske karijere, 1961. godine? A kako bi, ako bi, mlađi Bugarski na to danas reagovao starijem Bugarskom?

Teško pitanje! Opet imamo raspon od pedesetak godina - period tokom kojeg su se prilike za naučno sazrevanje i istraživanje promenile tako drastično da je današnjim početnicima u lingvistici teško i da zamisle kako su stvari izgledale na početku ovog raspona. U skladu s prilikom, ilustrovaću to ličnim primerom. Ja sam, kao pripadnik prve generacije studenata germanistike (a. engleski jezik i književnost, b. nemački jezik i književnost) na Filozofskom fakultetu u Sarajevu, diplomirao 1957. godine sa najvišim ocenama - a da pritom takoreći nisam ni čuo za lingvistiku. Bilo je tu, razume se, kurseva iz fonetike, gramatike i istorije jednog i drugog jezika, ali nikakvog uvodnog tečaja iz lingvistike, kakav bi se danas podrazumevao na jezičkim studijama. Jedina knjiga iz nauke o jeziku koju sam uspeo da pronađem u oskudno snabdevenoj katedarskoj biblioteci bio je Sapirov klasik Language: An Introduction to the Study of Speech iz 1921. godine, u najvećoj meri zaslužan za moje potonje opredeljenje da se posvetim lingvistici. (Uzgred, pozdravljam prisutnu profesorku Jasminu Grković Mejdžor, koja će mnogo kasnije, baš ovde u Novom Sadu, prevesti ovu knjigu na srpskohrvatski i snabdeti je uputnim predgovorom.)

Moj dalji put bio je trasiran po prelasku na Filološki fakultet u Beogradu, i naročito zahvaljujući daljim studijama u Londonu i Njujorku, gde sam nadoknađivao izgubljeno vreme grozničavim preturanjem po knjigama i 
kompletima časopisa u odličnim tamošnjim bibliotekama. Tu sam se opremio i za pisanje doktorske disertacije, koje se proteglo na bezmalo šest godina - a zašto, to je upravo poenta cele ove priče. Naime, korpus za moje istraživanje činilo je petnaestak romana savremenih engleskih pisaca po mom izboru, u kojima sam marljivo podvlačio svaku pojavu svakog od „mojih” predloga, ispisujući ih potom u kontekstu, uz gramatičke anotacije, na stotine listića. To je, da podsetim, bilo vreme značajno pre pojave kompjutera u široj upotrebi, a pogotovo interneta, elektronskih korpusa i pretraživača. Time sam bio bitno hendikepiran u poređenju sa današnjim mladim istraživačima, kojima je toliko toga dostupno „na jedan klik”.

Ipak bih na osnovu svega doživljenog ,sebi mlađem” savetovao da se na vreme usmeri, da se ne rasipa na više strana nego da pronađe svoj domen istraživanja i sopstveni ugao posmatranja jezičkih pojava. Drugim rečima, da u tom pogledu manje nalikuje meni nego na primer Vama, od početka usredsređenom na izabrano šire područje leksikologije i leksikografije, uz prateće tvorbene, semantičke, pragmatičke i kontaktno-kontrastivne aspekte, gde postižete vrhunske rezultate. A kakva bi na to bila reakcija mlađeg Bugarskog - iskreno, to ne znam, ali nije isključeno da bi odvratio nešto u stilu ,More, ne smaraj, matori, ti si išao svojim putem a ja ću svojim, i dosta mi je pridika o tome kako je tvoj put bio posut trnjem dok mojim teku med i mleko! Imamo i mi mladi svojih problema, danas i ovde...".

Izuzetno vredan završni savet doajena srpske $i$ jugoslovenske lingvistike, koji bi trebalo da postane putokaz svim mladim, budućim $i$ sadašnjim, lingvistkinjama i lingvistima na svim meridijanima. I u njihovo ime, najlepše Vam hvala, Profesore! 
